\title{
A importância dos catadores de materiais recicláveis no processo de gestão ambiental dos resíduos sólidos urbanos: breves reflexões na cidade de Campina Grande/PB
}

\section{1 | Introdução}

O aumento da população, associado ao incremento da necessidade de produção de alimentos e bens de consumo, leva o homem a transformar cada vez mais a matéria-prima gerando maiores quantidades de resíduos, tanto no processo de produção industrial quanto no consumo (DIAS; SALGADO, 1999). Fato corroborado por Marques (2005), que afirma que praticamente não se pode apontar uma atividade humana que não gere resíduos ou que não interfira de uma ou de outra forma com as condições do meio. Tal constatação é importante para o estudo das medidas adequadas para manter o fenômeno sob controle, principalmente no que concerne ao seu destino final, uma vez que, na maioria das cidades brasileiras, este destino termina por ser os "lixões". A presença dos "lixões" nos centros urbanos ocasiona diversos problemas, tanto para o meio ambiente como para a sociedade, dentre os quais se destaca a inserção de uma parcela da população, que sem outras perspectivas, busca nos resíduos seu alimento e sua fonte de renda, esta proveniente da venda dos materiais recicláveis lá encontrados.

Nesse sentido a coleta seletiva na fonte deve ser incentivada, e o máximo aproveitamento dos resíduos sólidos deve ser feito antes deles chegarem aos "lixões" ou aterros sanitários, de forma a extinguir a coleta de resíduos em "lixões" por famílias inteiras, incluindo crianças.
A estas famílias deve ser concedida prioridade de emprego em empresas de coleta seletiva de resíduos urbanos. Fato este que infelizmente não faz parte da realidade da cidade de Campina Grande/PB, considerada uma das principais cidades do interior do Nordeste, mas que ainda não possui nenhuma política pública para a inclusão social dos catadores de materiais recicláveis no processo de gestão integrada dos resíduos sólidos urbanos gerados pela municipalidade. A situação desses trabalhadores, principalmente dos que exerciam suas atividades laborais no interior do lixão municipal, se agravou com o encerramento da disposição final dos resíduos no citado ambiente, fazendo com que inúmeras famílias ficassem sem o seu principal meio de subsistência - os recicláveis ali existentes.

O trabalho em foco objetiva ressaltar o papel do catador de materiais recicláveis no processo de gestão dos resíduos sólidos, haja vista que a reciclagem de materiais reduz a exploração dos recursos naturais (às vezes no limite de sua oferta) e gasta menos energia para retornar esses materiais ao mercado consumidor. Ao mesmo tempo, este trabalho reflete a realidade dos catadores da cidade de Campina Grande/PB, após o encerramento da disposição final dos resíduos no ambiente do lixão municipal. 


\section{2 | Materiais e métodos}

Para realização deste trabalho, recorreu-se, primeiramente, a uma pesquisa de gabinete, através de levantamentos bibliográficos e documentais referentes à temática em estudo, buscando em livros, periódicos eletrônicos, anais de congressos, dissertações e teses, leis e decretos, a fundamentação necessária para as discussões ora propostas. Posteriormente, foi feita observações in loco de modo a evidenciar a situação atual do lixão de Campina Grande/ PB e ressaltar as condições de vida de alguns catadores que ainda permanecem no local. Ressalta-se que, em virtude de os resíduos não mais estarem sendo dispostos neste ambiente, houve uma grande dispersão dos catadores que ali trabalhavam, inviabilizando a possibilidade de aferir o depoimento do maior número possível de catadores. Por este motivo, faz-se oportuno registrar que o objetivo principal desta pesquisa refere-se aos fatores qualitativos que envolvem a temática estudada porque se acredita na importância de compreender a relação de dependência da categoria ora analisada para com os resíduos e o ambiente de trabalho - o "lixão". Dessa forma, a presente pesquisa se caracteriza por ser uma pesquisa descritiva, com a intenção de correlacionar a má disposição dos resíduos sólidos urbanos à atividade de catação desenvolvida por catadores de materiais recicláveis, enfatizando sua importância no processo de gestão ambiental.

Levando em consideração a Resolução 196/96 (BRASIL, 1996), estabelecida pelo Conselho Nacional de Saúde, a qual determina a apresentação de Termo de Consentimento Livre e Esclarecido (TCLE) em pesquisas que envolvam seres humanos, os trabalhadores foram informados da pesquisa, participaram voluntariamente e assinaram o termo supracitado concordando com a publicação científica dos resultados compilados e de maneira imparcial.

\section{3 | Resultados e discussões}

\section{Os catadores de materiais recicláveis e sua importância na gestão dos resíduos sólidos urbanos}

A figura dos catadores surge como resultado da economia de mercado na qual estamos inseridos, uma economia marcada pelo alto pa- drão de consumo e pela ampliação da exclusão social. Como resultado direto do modelo econômico capitalista e da lógica do mercado em produzir cada vez mais, os resíduos surgem, por um lado, como um dos grandes problemas ambientais na atualidade (LAYRAGUES, 2002; FADINI et. al., 2001), caso se considere que a geração de resíduos é algo irremediável, diante dos padrões de consumo vigente, e, por outro, como uma fonte de renda e subsistência para milhares de pessoas que dependem diretamente da venda dos materiais recicláveis presentes no "lixo".

De acordo com Demajorovic (2006), o trabalho de coleta de materiais recicláveis restringiu-se durante décadas aos grupos de catadores de rua nos grandes centros urbanos. $O$ descaso do setor público e dos movimentos sociais em relação à sua importância como agentes efetivos da coleta seletiva contribuiu para que seu trabalho permanecesse marginalizado e impediu qualquer iniciativa de organização ou de desenvolvimento de parcerias entre o setor público e os grupos organizados. Assim, os catadores passaram a integrar o sistema de gerenciamento de resíduos sólidos em alguns municípios, no final dos anos 1980 e início da década de 1990. Além dos fatores citados acima, o próprio crescimento da capacidade organizativa desses grupos foi essencial nesse processo de interlocução.

Os programas de gestão compartilhada geram uma série de benefícios. Em primeiro lugar, almejam valorizar o trabalho do catador, promovendo o resgate da cidadania e a inclusão social. Outro benefício importante dos programas de gestão compartilhada é a garantia de maior quantidade e de melhor qualidade do material reciclável, contribuindo para aumentar as oportunidades de venda direta às indústrias por melhores preços. Nesse sentido, o modelo de gestão compartilhada envolvendo a participação da Prefeitura, dos grupos organizados de catadores e da comunidade local propicia benefícios socioambientais e financeiros ao desviar parcela de resíduos dos aterros sanitários para a reciclagem, gerando renda para os catadores. Do ponto de vista da administração pública, este modelo de gestão é extremamente positivo, pois apresenta um aumento da eficiência e uma significativa redução dos 
custos dos programas de coleta seletiva de "lixo" (DEMAJOROVIC, 2006).

\section{A atividade de catação no contexto da realidade da cidade de Campina Grande/PB}

Distante $120 \mathrm{Km}$ da capital João Pessoa, Campina Grande está situada entre a altitude de 550 e $558 \mathrm{~m}$ e possui as seguintes coordenadas geográficas: Latitude de $7^{\circ} 13^{\prime} 50^{\prime \prime}$ Sul e Longitude de $35^{\circ} 52^{\prime} 52^{\prime \prime}$ W.GR. De acordo com o último Censo Demográfico, realizado no ano de 2010, a sua população é de 385.213 habitantes, dos quais $95,33 \%$ vivem na zona urbana.

De acordo com a Diretoria de Limpeza Urbana da Secretaria de Obras e Serviços Urbanos (SOSUR) de Campina Grande, em visita realizada no ano de 2009, a quantidade de resíduos coletados diariamente é superior a 500 toneladas. Deste total, cerca de $40 \%$ são de resíduos sólidos recicláveis, material que "alimenta" a atividade de "catação" no "lixão" municipal; outros 50\% são compostos por matéria orgânica, que, igualmente aos resíduos recicláveis, também podem ser reaproveitados (por exemplo, através da compostagem). Pode-se dizer que, do montante total de resíduos diários, apenas $10 \%$ poderia ser considerado rejeito, ou seja, material que não possui mais nenhuma forma de beneficiamento.

Grande montante dos resíduos gerados era destinado ao "lixão" municipal de Campina Grande/PB, localizado na Alça Sudoeste da cidade, Rodovia BR-230, distante cerca de $8 \mathrm{~km}$ do centro urbano, ocupando uma área de 35 hectares, perto de bairros residenciais (como o Bairro do Mutirão) e do aeroporto João Suassuna.

Assim como em outras cidades do Brasil, Campina Grande conta com a presença dos catadores de materiais recicláveis. De acordo com informações não oficiais (obtidas, em 2009, de representantes da Secretaria Municipal de Assistência Social, da presidente da Cooperativa de Catadores COTRAMARE e dos responsáveis pelo Projeto Esperança), cerca de 450 catadores retiram sua sobrevivência do lixão municipal. Desde total, cerca de 10\% é constituído de crianças e adolescentes que catam resíduos com os pais para complementar a renda familiar. Afora os catadores do lixão, aproximadamente 100 catadores realizam atividades nos bairros e no centro da cidade.

A atividade de catação deve, portanto, mobilizar entre 550 a 600 pessoas na cidade em estudo - menos de $2 \%$ da população - e poderia passar despercebida, não fosse a forma degradante em que a atividade em foco é desenvolvida.

Em 5 de janeiro de 2012, o poder público municipal da cidade de Campina Grande encerrou a atividade de disposição final dos resíduos sólidos urbanos gerados no município, não sendo estes mais levados, a partir da referida data, para as instalações do lixão municipal e sim para um aterro construído no município de Puxinanã, cidade que compõem a Região Metropolitana de Campina Grande, funcionando, esta obra de engenharia, de forma consorciada com outros municípios da região. Todavia, o encerramento da disposição de resíduos no lixão municipal não implicou sua extinção - os resíduos que ainda se encontram ali depositados continuam a prejudicar o meio ambiente e a sociedade.

As famílias que retiravam o seu sustento do lixão não foram incluídas no processo de gestão integrada de resíduos sólidos. Elas ficaram sem nenhuma garantia de renda. Por este motivo, o lixão desativado provavelmente ainda exerce grande influência na condição socioeconômica dos trabalhadores em questão, atraindo algumas famílias para a retirada dos recicláveis restantes. Fato este constatado quando da observação in loco, quando foi possível identificar pessoas que continuavam a residir no lixão e a retirar o pouco dos recicláveis que sobraram.

Como forma de suprir as famílias que trabaIhavam no lixão, a prefeitura municipal passou a disponibilizar uma cesta básica e uma ajuda de custo mensal no valor de $\mathrm{R} \$ 100,00$ (cem reais). Mas este auxílio está suspenso temporariamente conforme informado pelo Secretário Municipal de Assistência Social, quando este ressalta a necessidade "de uma dotação orçamentária para continuar com o benefício financeiro, o que deve ser aprovado pela Câmara Municipal, mas as cestas básicas continuarão a ser doadas" (ALENCAR, 2012). Apesar da importância que a atividade em foco representa para o processo de gestão dos resíduos e do seu reconhecimento como nova categoria de trabalho (classificada pelo Ministério do TrabaIho através do Decreto 397, publicado no Diário Oficial da União em 10 de outubro de 2002, e identificada como ocupação brasileira, sob o código 5192-05, recebendo como denomina- 
ção o seguinte título: "Catadores de Materiais Recicláveis" (BRASIL, 2002)), a mesma não vem recebendo tal reconhecimento por parte do poder público municipal, visto que até o momento não foi observado qualquer iniciativa visando à inclusão social desses trabalhadores, tampouco a adoção de programas de coleta seletiva, com implantação de centrais de triagem e compostagem, sendo encaminhado para o aterro apenas o material considerado sem nenhum valor econômico agregado, conforme determina a atual Política Nacional de Resíduos Sólidos - Lei n 12.305/2010 (BRASIL, 2010), como forma de minimizar os impactos ambientais decorrentes da gestão inadequada dos resíduos sólidos urbanos.

\section{4 | Conclusão}

A atividade de catação de materiais recicláveis já foi reconhecida como categoria de trabalho e, portanto, tais trabalhadores deveriam ser tratados com dignidade, haja vista o benefício decorrente do trabalho por eles desenvolvido.

A Política Nacional de Resíduos Sólidos (BRASIL, 2010) em vigor estabelece que o poder público municipal deve incluir os catadores de materiais recicláveis na gestão municipal dos resíduos, como forma de garantir renda e melhor qualidade de vida e trabalho para estas pessoas.

O que se percebe em Campina Grande, é que estes trabalhadores foram relegados à própria sorte, ficaram desprovidos da fonte de sua renda e da ajuda do poder público municipal, o que agravou um problema socioeconômico, tanto para os catadores, como para a economia local, haja vista a redução do volume dos recicláveis coletados após o encerramento do lixão municipal, uma vez que este processo (encerramento das atividades de disposição final dos resíduos) ocorreu sem que houvesse nenhum planejamento técnico que a situação requer, ressaltando a ineficiência para com a gestão dos resíduos.

\section{Referências bibliográficas}

ALENCAR, I. Catadores continuam no antigo lixão de Campina Grande. Jornal da Paraíba. Caderno Cidades, p. 3, 12 jul. 2012.

BRASIL, Presidência da República. Ministério do Trabalho e Emprego. Decreto Federal n 397, de og de outubro de 2002. Aprova a Classificação Brasileira de Ocupações - $\mathrm{CBO} / 2002$, para uso em todo território nacional e autoriza a sua publicação.

BRASIL, Governo Federal. Ministério da Saúde. Conselho Nacional de Saúde.

Resolução 196/96 de 10 de outubro de 1996. Estabelece diretrizes e normas regulamentadoras de pesquisas envolvendo seres humanos. Disponível em: <conselho. saude.gov.br/resolucoes/1996/reso196.doc>. Acesso em: set. 2011.

BRASIL, Presidência da República. Casa Civil. Lei no. 12.305, de 02 de agosto de 2010. Institui a Política Nacional de Resíduos Sólidos. Disponível em: <www.planalto.gov. br/ccivil_03/_ato2007-2010/2010/lei/l12305. htm>. Acesso: out. 2010.

DEMAJOROVIC, J. et. al. Os desafios da gestão compartilhada de resíduos sólidos face à lógica do mercado. In: JACOBI, P.; FERREIRA, L. C. Diálogos em ambiente e sociedade no Brasil. São Paulo: ANPPAS, Annablume, 2006.

DIAS, J. A.; SALGADO, M. G. Manual do procurador público. Programa Lixo e Cidadania: criança no lixo nunca mais. Procuradoria geral da República. Brasília, 1999.

FADINI, P. S. e.t al. Lixo: desafios e compromissos. São Paulo. Cadernos Temáticos de Química Nova na Escola, n. 1, p. 9-18, mai. 2001. 
GONÇALVES, P. A reciclagem: integradora

dos aspectos ambientais, sociais e econômico.

Rio de Janeiro: DP\&A, Fase, 2003.

LAYRARARGUES, P. P. O cinismo da

reciclagem: o significado ideológico da

reciclagem da lata de alumínio e suas

implicações para a educação ambiental. In:

CATRO, R. S. et. al. Educação Ambiental:

repensando o espaço da cidadania. São Paulo:

Cortez, 2002.

MARQUES, J. R. Meio ambiente urbano. Rio

de Janeiro: Forense Universitária. 2005.

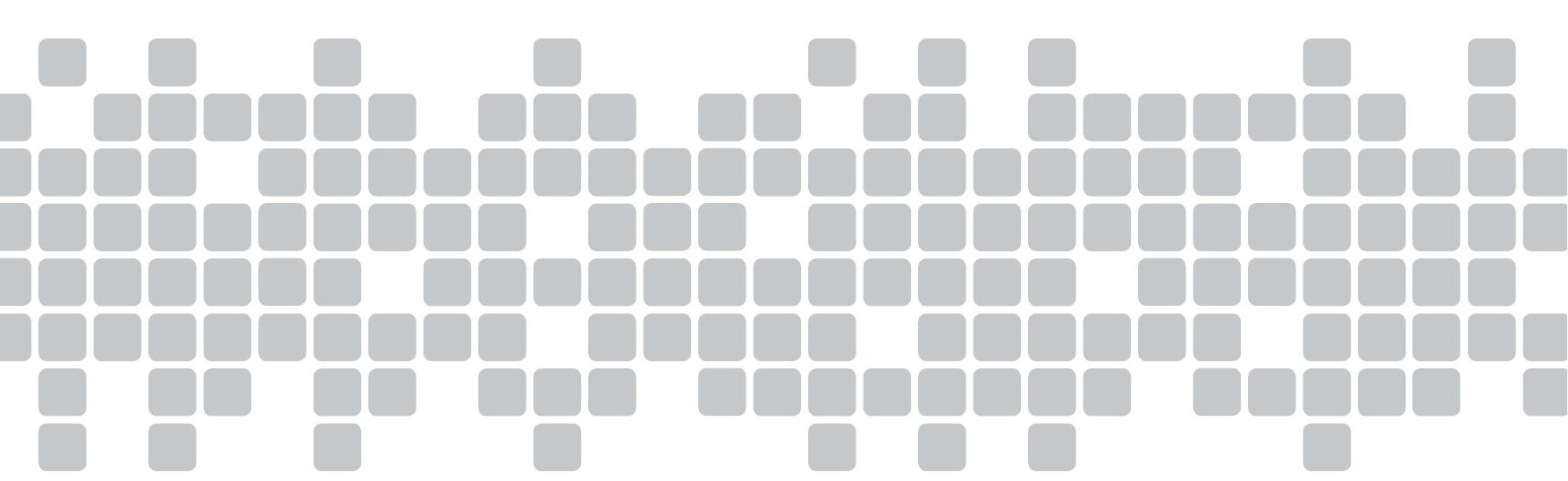

